\title{
Growing poplars for research with and without mycorrhizas
}

\section{Anna Müller ${ }^{\dagger}$, Katharina Volmer ${ }^{\dagger}$, Manika Mishra-Knyrim and Andrea Polle *}

Forest Botany and Tree Physiology, Büsgen-Institut, Georg-August Universität Göttingen, Göttingen, Germany

\section{Edited by:}

Karin Köhl, Max Planck Institute of

Molecular Plant Physiology,

Germany

Reviewed by:

Brian Grout, University of

Copenhagen, Denmark

Noel Ferro Diaz, University of Bonn,

Germany

\section{*Correspondence:}

Andrea Polle, Forstbotanik und

Baumphysiologie, Georg-August

Universität Göttingen, Büsgenweg

2, 37077 Göttingen, Germany

e-mail: apolle@gwdg.de

tThese authors have contributed equally to this work.
During the last decades the importance of the genus Populus increased because the poplar genome has been sequenced and molecular tools for basic research have become available. Poplar species occur in different habitats and harbor large genetic variation, which can be exploited for economic applications and for increasing our knowledge on the basic molecular mechanisms of the woody life style. Poplars are, therefore, employed to unravel the molecular mechanisms of wood formation, stress tolerance, tree nutrition and interaction with other organisms such as pathogens or mycorrhiza. The basis of these investigations is the reproducible production of homogeneous plant material. In this method paper we describe techniques and growth conditions for the in vitro propagation of different poplar species (Populus $\times$ canescens, P. trichocarpa, $P$. tremula, and $P$. euphratica) and ectomycorrhizal fungi (Laccaria bicolor, Paxillus involutus) as well as for their co-cultivation for ectomycorrhizal synthesis. Maintenance and plant preparation require different multiplication and rooting media. Growth systems to cultivate poplars under axenic conditions in agar and sand cultures with and without mycorrhizal fungi are described. Transfer of the plants from in vitro to in situ conditions is critical and hardening is important to prevent high mortality. Growth and vitality of the trees in vitro and outdoors with and without ectomycorrhizas are reported.

Keywords: poplar, mycorrhiza, fungi, laboratory protocols, in vitro, plant growth, micropropagation

\section{INTRODUCTION}

Among woody plant genera, the genus Populus is of increasing economic and scientific importance. The genus consists of six sections with about 30-35 poplar species world-wide (Eckenwalder, 1996). The species occur in riparian and forest ecosystems across the Northern Temperate Zone from the polar circle to $30^{\circ}$ north latitude (Lubrano, 1992; Dickmann, 2001). The economic value and natural distribution of the genus Populus varies between the sections. Some species, e.g., $P$. tremuloides and $P$. tremula have extensive distribution ranges across whole North America and Eurasia, respectively, whereas others are confined to distinct regions (Dickmann, 2001). The genetic variability within the genus allows for the selection of genotypes that are adapted to different site conditions such as poor, degraded, or polluted soils (Lubrano, 1992; Doty, 2008; Chen and Polle, 2010). Populus species and hybrids are grown worldwide for plywood, lumber, paper, woody biomass, and bioenergy production (Polle and Douglas, 2010; Sannigrahi et al., 2010; Polle et al., 2013).

Because of their increasing importance for biomass production and the availability of molecular tools, poplars are studied in a vast range of research areas such as wood formation and wood properties (Plomion et al., 2001; Pilate et al., 2004; Janz et al., 2012), nutrition (Harvey and van den Driessche, 1997; Cooke and Weih, 2005; Lukac et al., 2010; Rennenberg et al., 2010), stress (Wullschleger et al., 2009; Beniwal et al., 2010; Chen and Polle, 2010; Janz et al., 2010), seasonality (Brunner and Nilsson, 2004; Rohde et al., 2011; Larisch et al., 2012), interactions with other organisms including mycorrhizal fungi (Philippe and Bohlmann, 2007; Felten et al., 2009; Luo et al., 2009; Nehls et al., 2010; Schnitzler et al., 2010). Populus is a well-established model tree for biotechnology and molecular biology research due to the availability of the fully sequenced genome of Populus trichocarpa (Torr. and Gray) genotype "Nisqually-1" (Tuskan et al., 2006), the ease of in vitro cultivation (Kang and Chun, 1997; Kang et al., 2009) and the ease of vegetative propagation by cuttings, except aspen (Lubrano, 1992; Confalonieri et al., 2003).

Cloning of poplars in vitro enables the production of homogeneous plant material throughout the year (McCown, 1997; Kang et al., 2009). In vitro micropropagation is one of the most important multiplication techniques for different purposes like breeding, genetic and biotechnological research, and mass production of commercial clones (Nool et al., 2002; Altman, 2003; Confalonieri et al., 2003; Häggman et al., 2007; Yadav et al., 2009).

Most of the existing studies on poplar growth protocols focus on a single poplar species (Iordan-Costache et al., 1995; Phan et al., 2004; Kang et al., 2009; Peternel et al., 2009; Thakur et al., 2012). In the present paper we report differing techniques and growth conditions for different poplar species. We describe the micropropagation of the species P. trichocarpa (section Tacamahaca), P. tremula (section Populus), P. euphratica (section Turanga), and the hybrid Populus $\times$ canescens (syn. $P$. tremula $\times$ P. alba) under axenic conditions and the transfer of the plantlets into soil for outdoor experiments.

Further attention has been paid to the cultivation of poplar with ectomycorrhizal fungi because those interactions are a hallmark of forest trees, important for tree nutrition and stress tolerance (Nehls et al., 2010; Habib et al., 2013). Growth of the symbiotic partners together under axenic conditions is important for the elucidation of the underlying molecular processes. 
We, therefore, also describe growth conditions for Laccaria bicolor and Paxillus involutus, which are well-established ectomycorrhizal model systems for the establishment of the symbiotic interaction with poplar. The genome of $L$. bicolor is available and that of $P$. involutus is currently being sequenced (Martin et al., 2008; Marmeisse et al., 2013). Therefore, the combination of poplar with sequenced model fungi is especially useful to unravel the molecular ecology of tree-mycorrhizal interactions.

The goal of this work is to describe well-established protocols, give practical advice and examples for the work with poplars and their ectomycorrhizal associates. The first step before micropropagation can start is the establishment of tissue cultures from field-grown trees. Protocols for shoot regeneration from tissue explants have been reported for a number of poplar species (Vinocur et al., 2000; Noël et al., 2002; Phan et al., 2004; Yadav et al., 2009; Maheshwari and Kovalchuk, 2011) and readers are referred to those studies. Here, we focus on the in vitro multiplication of different poplar species and their preparation for different experimental approaches under highly controlled axenic or outdoor conditions. To guide the reader through the different stages of poplar and fungal cultivation together or separately, we present a flow chart for the work schedule (Figure 1). The subheadings of the different protocols and propagation steps are repeated in the flow chart to facilitate cross-referencing.

\section{AXENIC MULTIPLICATION OF POPLAR}

For research purposes homogeneous plant material for the replication of the experiments is essential. For the micropropagation of Populus $\times$ canescens, $P$. trichocarpa, P. tremula, and $P$. euphratica media based on the original protocols of Murashige and Skoog (1962) (=MS medium) and Lloyd and McCown

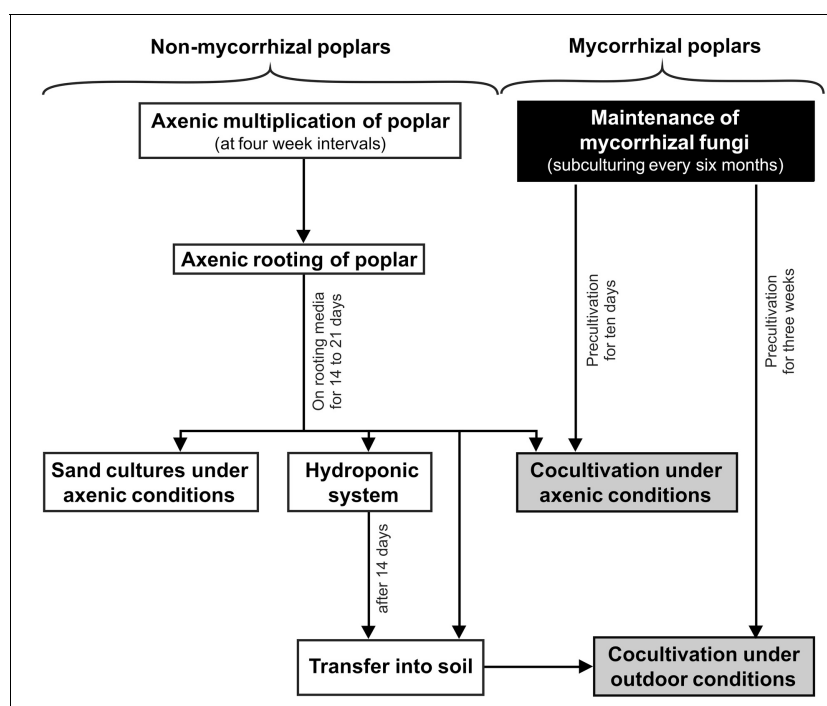

FIGURE 1 | Flow chart for growing poplars (Populus sp.) under mycorrhizal or non-mycorrhizal conditions. The chart displays poplar growth conditions for axenic or outdoor cultivation (white color), for the cultivation of mycorrhizal fungi (black color), and the co-cultivation of mycorrhizal fungi and poplar (gray color). Approximated cultivation times are indicated.
(1980) for woody plants (=WPM medium) were used. Suitable multiplication media for different poplar species are listed in Table 1 and the composition of the media has been compiled in Table 2.

For micropropagation, we used glass jars (Schott, Jena, Germany) with a diameter of $14 \mathrm{~cm}$ and a height of $5 \mathrm{~cm}$. The jars were covered with a glass Petri dish (Schott, Jena, Germany). After selection of the multiplication medium (Tables 1, 2), it was solidified with $3 \%$ Gelrite. MS medium was used as the basis medium for micropropagation. Its $\mathrm{pH}$ value was adjusted to 5.8 before sterilization by autoclaving (HST $6 \times 6 \times 6$, Zirbus Technology $\mathrm{GmbH}$, Bad Grund, Germany) at $121^{\circ} \mathrm{C}$ and 2.2 bar for $20 \mathrm{~min}$. All procedures, which require sterile conditions, were carried out under laminar air flow (Typ S2020 1.8, Thermo Scientific, Schwerte, Germany). For multiplication of the various poplar species, we used approximately $1-2 \mathrm{~cm}$ long stem cuttings of ca. 4-week-old plantlets, each containing one leaf. About 10-15 cuttings were transferred vertically into one glass jar containing an about $2 \mathrm{~cm}$ thick layer of half-strength MS medium. The glass jars were then sealed with Parafilm ${ }^{\mathrm{TM}}$ (Bemis Flexible Packing, Neenah WI, USA) and incubated in a growth room under controlled environmental conditions $\left[26^{\circ} \mathrm{C}, 60 \%\right.$ relative air humidity, $16 \mathrm{~h} / 8 \mathrm{~h}$ light/dark cycle with a photosynthetic active radiation (PAR) of $150 \mu \mathrm{mol}$ photons $\mathrm{m}^{-2} \mathrm{~s}^{-1}$ at plant height supplied by lamps (Osram 18W/640 white light, München Germany)]. After 4 weeks, the plantlets had a height of about 4-6 cm and 6-8 leaves. The plantlets were then used for further multiplication, by separating the shoot into $1-2 \mathrm{~cm}$ long cuttings each containing one leaf. The multiplication medium does not induce root formation and is, therefore, mainly used for the maintenance of stock cultures and production of high numbers of shoot cuttings under controlled conditions. All stock cultures were maintained in duplicates or triplicates.

One risk of micropropagation is the contamination of the cultures with microorganisms. Therefore, the glass jars were checked regularly for any kind of visible contamination. Jars with contaminated plantlets were immediately disposed. When transgenic plantlets had to be discarded, the media and plantlets were sterilized $\left(121^{\circ} \mathrm{C}, 20 \mathrm{~min}, 2.2 \mathrm{bar}\right)$.

For optimal performance of the plantlets in the subsequent experiments, the growth media for the poplar species (see Table 1), the right size of the plantlets and also the jar size has

Table 1 | Multiplication and rooting media for different poplar species.

\begin{tabular}{llllll}
\hline Poplar species & \multicolumn{2}{c}{ Multiplication media } & & \multicolumn{2}{c}{ Rooting Media } \\
\cline { 2 - 3 } & MS & WPM & & SH & WPM \\
\hline P. $\times$ canescens & $X$ & - & & $X$ & $X^{*}$ \\
P. trichocarpa & - & $X$ & & - & $X$ \\
P. tremula & $X$ & - & & $X$ & - \\
P. euphratica & $X$ & $X$ & & & $X$
\end{tabular}

Abbreviations refer to MS, Murashig \& Skoog, WPM, Woody Plant Medium, and SH, Schenk Hildebrandt media. Suitable medium are marked with an X.

${ }^{*}$ Rooting of $P . \times$ canescens on WPM medium is slower than on SH medium. 
Table 2 | Composition of Murashig \& Skoog (MS), Long Ashton (LA), Schenk Hildebrandt (SH), and Woody Plant Medium (WPM) for multiplication and rooting of poplar plantlets.

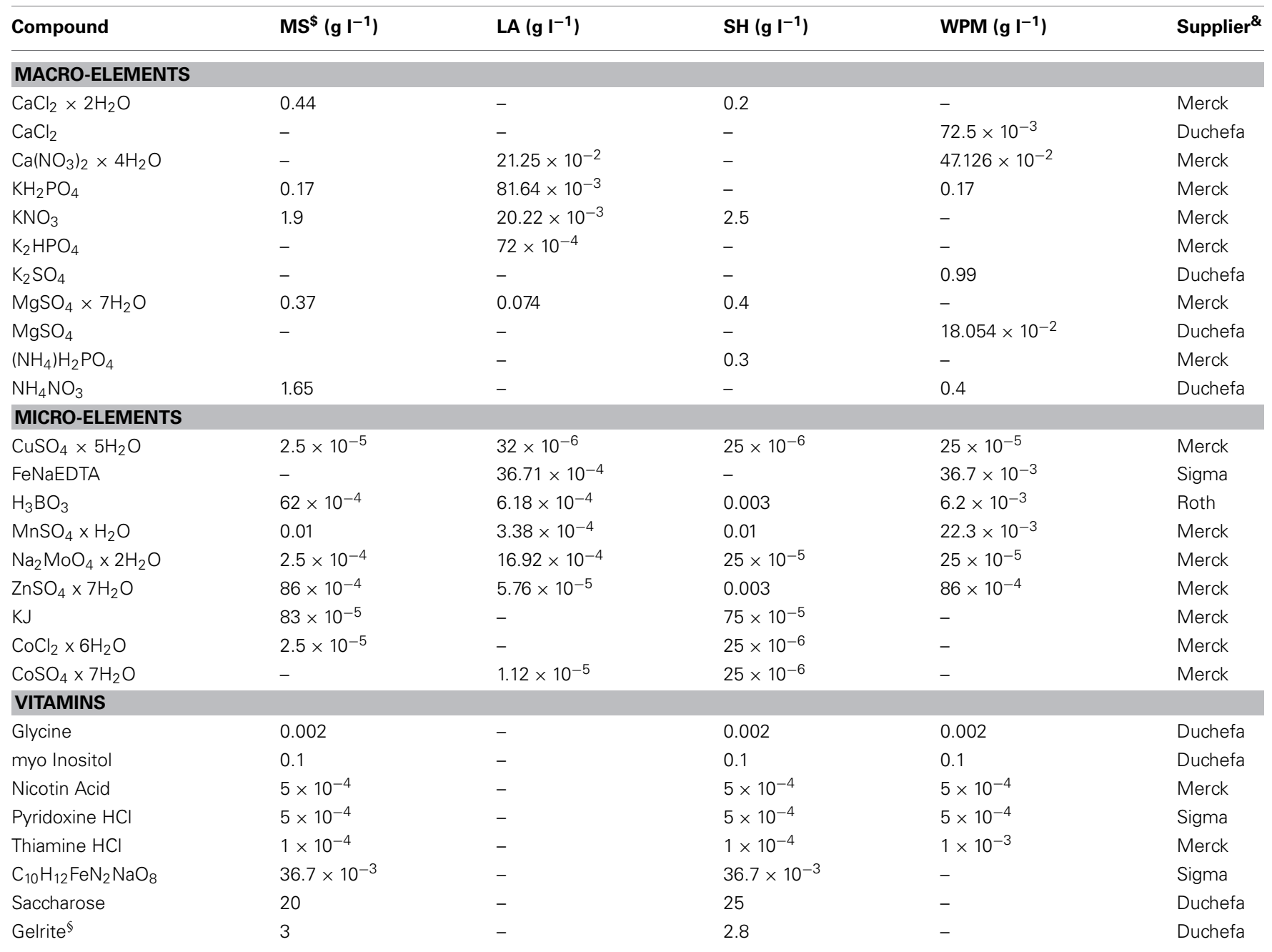

The concentrations are given as final concentrations.

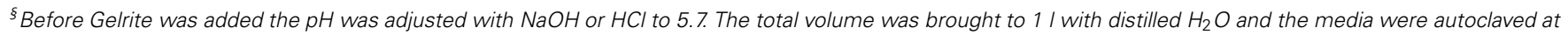
$121^{\circ} \mathrm{C}$ for $20 \mathrm{~min}$ at 2.2 bar.

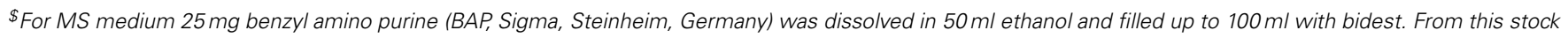
solution $0.8 \mathrm{~m} /$ was used for $1 /$ medium.

\& Suppliers: Carl Roth, Karlsruhe, Germany; Merck, Darmstadt, Germany; Duchefa, Haarlem, Netherlands; Sigma, Steinheim, Germany; Serva, Mannheim, Germany.

to be adapted. We are using glass jars of $7 \mathrm{~cm}$ height with $150 \mathrm{ml}$ medium for the culture of $P . \times$ canescens, $P$. euphratica, and $P$. tremula. Because $P$. trichocarpa grows faster than the other poplar species glass jars of $12 \mathrm{~cm}$ height with $150 \mathrm{ml}$ medium are recommended for the latter species. In case of suboptimal conditions, e.g., medium composition or space limitations, the plantlets can show symptoms of nutrient deficiencies or growth suppression during the experimental period (Poorter et al., 2012).

\section{AXENIC ROOTING OF POPLAR}

To induce rooting of the plantlets, the unrooted freshly cut microcuttings were transferred to either Schenk Hildebrandt (SH medium; Schenk and Hildebrandt, 1972) or to WPM with hormones (Tables 1, 2). Because of the different growth characteristics of different poplar species, the cuttings rooted within 14-21 days (cf. Figure 1).

\section{SAND CULTURES UNDER AXENIC CONDITIONS}

Rooted poplars can also be grown in sand as the supporting medium under axenic conditions. The plants are fertilized by addition of suitable nutrient solutions. The advantage of sand is that it can be easily sterilized and supports the formation of more typical root systems than agar or Gelrite-based media. The plantlets can be removed easily for further analyzes. The nutrition can be controlled by addition of fertilizer solution because the sand contains no nutrients.

In our study we grew $P . \times$ canescens and $P$. trichocarpa in sand cultures. For this purpose square Petri dishes $(12 \times 12 \mathrm{~cm}$, 
Carl Roth GmbH \& CoKG, Karsruhe, Germany) were equipped with a self-made spacer, which consisted of an $11 \mathrm{~cm}$ long flexible tube (Rotilab PVC tube, $\varnothing$ inside $6 \mathrm{~mm}$, outside $10 \mathrm{~mm}$, Carl Roth) connected with tube couplers (Carl Roth) on both ends for stabilization (Figures 2A-D). For the fixation of the plantlets, a small indentation was cut into the tube with a razor blade and the plantlet was inserted. The spacer was introduced at $4 \mathrm{~cm}$ from the bottom to fix the position of plants and soil. The lower part was filled with $75 \mathrm{~g}$ of autoclaved sand ( $\varnothing 0.71-1.25 \mathrm{~mm}$ particle size, Melo, Göttingen, Germany; Figure 2). We used plantlets that had been grown for $18 \mathrm{~d}$ on WPM medium (as described above). Plantlets with three to four roots with a length of $0.5-1 \mathrm{~cm}$ were transferred into the sand culture. $P . \times$ canescens or $P$. trichocarpa plantlets were carefully placed in the indentations of the spacer tube with the roots placed in the sand. An aliquot of $8 \mathrm{ml}$ of the sterilized growing medium (WPM) was added to the sand. Afterwards the Petri dishes were sealed with Parafilm and kept in a growth room under the same environmental conditions as before (see above). To prevent light exposure of the roots, the bottom halves of the Petri dishes were wrapped in foil. The plates were arranged vertically in self-made plastic racks for optimal light exposure and grown under same environmental conditions as before. We kept the plants in these systems for 5 weeks without further fertilizer addition (Figure 2). Growth was measured weekly by scanning the Petri dishes with a resolution of $300 \mathrm{dpi}$ (CanScan 4400F, Canon Inc, Tokyo, Japan) and image analysis software (DatInf ${ }^{\circledR}$ Measure 2.1, Tübingen, Germany). After 5 weeks of growth, the plantlets were harvested.

The cultivation period is limited by the size of the Petri dishes and nutrient availability. Figures $2 \mathbf{A}, \mathbf{C}$ show typical plantlets after insertion into the system and after 5 weeks when they had grown about $3 \mathrm{~cm}$ in height (Figures 2B,D). We did not observe significant differences in height or root biomass between $P . \times$ canescens and $P$. trichocarpa (Figures 2E,F).

\section{HYDROPONIC SYSTEMS}

Rooted poplars can easily be grown in hydro-cultures after acclimation. In this case water is the supporting medium. A waterbased culture has the advantage that it allows the access to the roots for e.g., physiological or biomass measurements during the experimental treatment (Poorter et al., 2012) and that the nutrient supply can be controlled.

We cultivated poplar plants in aerated hydroponic solutions in black covered or painted plastic containers filled with Long Ashton (LA) nutrient solution (Hewitt and Smith, 1975) (Table 2). Aeration was achieved by bubbling air, which was supplied by an in-house connection through the nutrient solution after filtering through quartz wool filters (HEKAtech $\mathrm{GmBH}$, Wegberg, Germany). The in vitro pre-cultured rooted plantlets were transferred into the LA solution after 3 weeks on rooting media. The containers were covered with a plastic lid into which holes had been drilled to insert the plants. The plants were fixed with small sponges in the perforated lid. The nutrient solution was renewed once a week or more frequently when the plants were very large. The plants were grown in the growth room as before (photoperiod of $16 \mathrm{~h}$ light and $8 \mathrm{~h}$ darkness and $150 \mu \mathrm{mol}$ quanta $\mathrm{m}^{-2} \mathrm{~s}^{-1}$ PAR at $26^{\circ} \mathrm{C}$ and $60 \%$ air humidity). After removal from the rooting medium, the plantlets are extremely sensitive to desiccation. It is, therefore, necessary to acclimatize the plantlets to ambient conditions. For this purpose, the plants were covered by
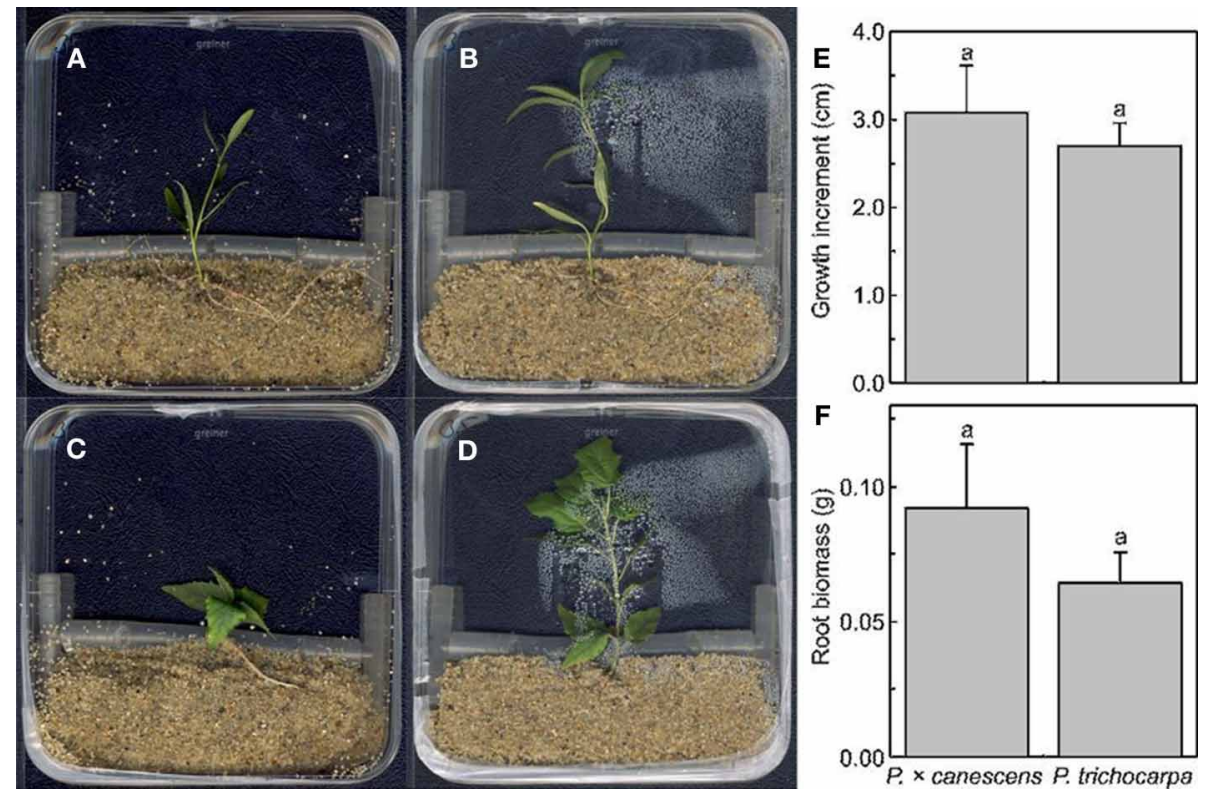

FIGURE 2 | Poplar plantlets in a Petri dish system under axenic conditions in sand. Petri dishes with $P$. trichocarpa immediately after planting (A) and after 5 weeks (B). Petri dishes with $P$. $\times$ canescens immediately after planting (C) and after 5 weeks (D).
Height increment (E) and fresh root biomass of $P$. trichocarpa and Populus $\times$ canescens after 5 weeks $(\mathbf{F})$. Data are means $( \pm S E$, $n=12$ ). The same letters indicate the absence of significant difference with $p<0.05$. 


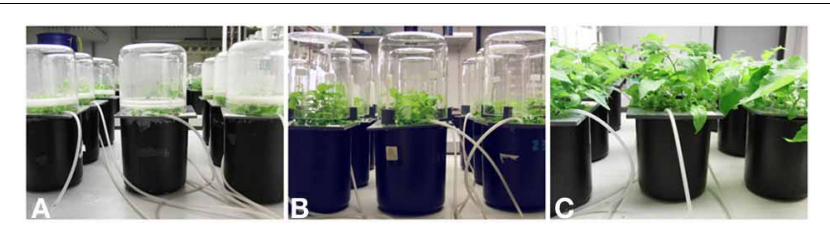

FIGURE 3 | Hardening of Populus $x$ canescens plantlets in a hydroponic system. The plants are shown after 1 week (A), 2 weeks (B), and 3 weeks (C) in hydroculture.

a glass beaker, which was gradually lifted during the course of 14 days (Figures 3A-C). We used hydroponically grown poplars to conduct salt stress experiments (Brinker et al., 2010; Janz et al., 2012) or to investigate the effects of heavy metals (Elobeid et al., 2011). We conducted our hydroponic experiments mainly in controlled growth rooms, but have also applied the system successfully under greenhouse conditions (e.g., Elobeid and Polle, 2012).

\section{TRANSFER INTO SOIL}

In vitro micropropagated poplar plantlets are not adapted to ambient outdoor conditions. They are acclimatized to high air humidity and a low UV irradiation. The leaves have a thin cuticle and a poor regulation of transpiration (Pospóšilová et al., 1999). Therefore, the transfer of poplars from in vitro to ex vitro conditions is a critical step, with a high risk of plant mortality. To prevent the plants from wilting, high relative air humidity has to be maintained during hardening. For hardening of poplar plantlets, it is possible to use hydroponic systems as described above. After 2 weeks the plants can be transferred into soil.

Another possibility is the direct transfer of micropropagated plants from the in vitro culture into soil or sand. Here, it is also important to keep the plants in high air humidity, which can be achieved by covering the plants with a transparent plastic bag for up to 2 weeks. The bag is gradually lifted. We potted the poplars in soil (Fruhstorfer Erde Type N, Hawite Gruppe GmBH, Vechta, Germany) or sand/peat mixtures [two parts of peat (REWE, Köln, Germany), eight parts coarse sand ( $\varnothing 0.71-1.25 \mathrm{~mm}$; Melo, Göttingen, Germany) and two parts fine sand (Ø $0.4-0.8 \mathrm{~mm}$; Melo, Göttingen, Germany)]. Growth in sand/peat requires regular fertilization. Cultivation in a sand/peat mixture is useful, if roots are to be analyzed or if controlled nutrient supply is important. Regular watering is important, especially for plants in sand/peat mixtures.

The plants can be grown in pots in acclimatized rooms, greenhouses, or outdoors. Recording of the environmental variables (light intensities, day/night lengths, air humidity, and temperatures) is necessary to control the experimental conditions. In the greenhouse, additional illumination may be required to achieve day lengths $>14 \mathrm{~h}$ when the plants are grown in seasons with short days. The size of the pot depends on the duration of the experiment.

In our studies Populus $\times$ canescens was grown for 2 months in 31 pots in Frühstorfer Erde Typ $\mathrm{N}$ under outdoor conditions (Figure 4). The potted plants were gradually acclimated to outdoor conditions by gradually increasing the exposure times

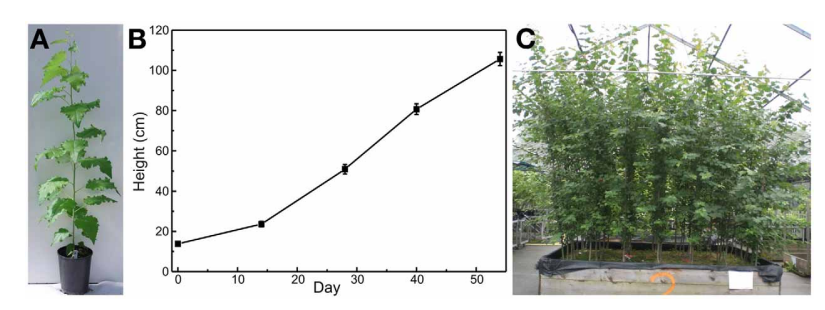

FIGURE 4 | Populus $\times$ canescens plant grown outdoors (A), height development during the growth phase of $\mathbf{5 4}$ days (B), and long-term growth in soil filled boxes (C). The potted poplars were grown in 31 pots from the day of planting to day 54 (mean \pm SE, $n=16$ ).

outdoors and initially avoiding full sun. After 54 days, the plants reached the height of about $1 \mathrm{~m}$ (Figure 4), an aboveground biomass of $14 \mathrm{~g}$ and a belowground biomass of $4 \mathrm{~g}$. If the plants are intended to be grown for longer time periods, pots with larger volumes, or use of large boxes are recommended (Figure 4). Selecting the correct pot size is a trade-off between a higher number of replicates (small pots) and a longer duration of the study (large pots or boxes). In the large boxes, we maintained poplars for up to 2 years and heights up to 2.5-3 m (Figure 4). With a governmental permission, growth of transgenic poplars under outdoor conditions is possible (e.g., Behnke et al., 2010, 2012). Field trials with transgenic poplars have also been reported (Walter et al., 2010; Danielsen et al., 2012). However, because of the strict regulation in many countries, such field trials are not common (Strauss et al., 2009).

\section{MAINTENANCE OF MYCORRHIZAL FUNGI}

For research on poplar-ectomycorrhizal fungal (EMF) interactions, the plant and the fungus have to be pregrown in parallel. Therefore, the maintenance of pure fungal cultures is essential. It enables a replication of experiments and the use of the same fungal isolates for further studies. Over the last decades, the techniques and methods for preservation of fungal isolates have been improved. We describe suitable media, growth conditions, and cultivation periods for Laccaria bicolor and Paxillus involutus.

Media useful for fungal stock cultures are, e.g., MelinNorkrans medium and the Pachlewski medium. We used a modified Melin-Norkrans medium (MMN) or the Pachlewski media P05 for the maintenance of ectomycorrhizal fungi (after Marx, 1969; Deveau et al., 2007). The compositions of the media are listed in Table 3.

For maintenance of stock cultures Petri dishes with a diameter of $10 \mathrm{~cm}$ were filled with $30 \mathrm{ml}$ medium and inoculated with a single fungal plug (diameter $=1 \mathrm{~cm}$ ) in the center. The plates were sealed with Parafilm and kept under controlled-environmental growth conditions at $23^{\circ} \mathrm{C}$ in permanent darkness to produce materials for experiments. For storage, cultures were kept at $4^{\circ} \mathrm{C}$ in permanent darkness on MMN media and subcultured onto the MMN media every 6 months.

One risk of frequent subculturing, especially while working with different fungal isolates, is the chance of contamination of the cultures. Therefore, meticulous attention has to be paid 
to sterility. The identity of the fungal species should be confirmed regularly by molecular analysis of the internal transcribed spacer sequence (ITS) as described elsewhere (Lang et al., 2011). Saprotrophic long-term cultures of ectomycorrhizal fungi may result in the loss of the ability of the EMF to form functional symbiosis. Therefore, most EMF must occasionally be employed to form ectomycorrhizas with a suitable host and then re-isolated from the roots. However, to our experience this is not required for Paxillus involutus (strain MAJ), which we used the last 15 years (Brandes et al., 1998), neither for Laccaria bicolor (strain S238N Maire P.D. Orton provided by F. Martin, INRA, Nancy, France), which has been successfully used for about 20 years (Henrion et al., 1994). Petri dish systems with synthetic media can be used to investigate the performance of the ectomycorrhizal fungi in absence of their hosts. For example, Müller et al. (2013) revealed profound differences in the volatile profiles of EMF including $P$. involutus and L. bicolor, which may play roles in plant-fungal communication.

\section{COCULTIVATION UNDER AXENIC CONDITIONS}

Culture systems for the cultivation of poplars with $L$. bicolor or $P$. involutus under in vitro conditions have been described, e.g., by Felten et al. (2009) and Gafur et al. (2004). We successfully used a modified co-culture system after Felten et al. (2009), in which L. bicolor was pregrown on a cellophane membrane
(Deti GmbH, Meckesheim, Germany) on top of Pachlewski medium P20 (Table 3). Advantages of using cellophane on top of a media are the supply of the fungus with all necessary nutrients, while at the same time preventing its growth into the medium. This allows the fungus to be easily transferred from one Petri dish to a new Petri dish or its use for analyses.

Square Petri dishes $(12 \times 12 \mathrm{~cm})$ were filled with $50 \mathrm{ml}$ sugarreduced P20 medium. Cellophane membranes were cut into halves $(6 \times 12 \mathrm{~cm})$. The membranes were first boiled twice for $30 \mathrm{~min}$ in distilled water and subsequently autoclaved twice. Two membranes were placed in one Petri dish onto the P20 medium next to each other (Figure 5A). Eleven fungal plugs of Laccaria bicolor cultures, which had been pre-cultured on P05 media, were placed on the membrane (Figure 5A). The Petri dishes were sealed with Parafilm and kept at $23^{\circ} \mathrm{C}$ in permanent darkness. The regular placement of the fungal plugs on the cellophane membranes ensured the regular coverage of the cellophane surface with actively growing fungal mycelium after 10 days of culture. The arrangement on the cellophane membrane as well as the precultivation time should be adjusted according to the growth of the fungus. It is therefore recommended to analyze the growth of the fungus on the used media before starting the final experiment.

For inoculation with $L$. bicolor, $P . \times$ canescens was micropropagated in vitro and grown on rooting media in glass jars for 3 weeks

Table 3 | Composition of the modified Melin-Norkrans medium (MMN), the Pachlewski medium (P05), and the sugar-reduced Pachlewski medium (P20).

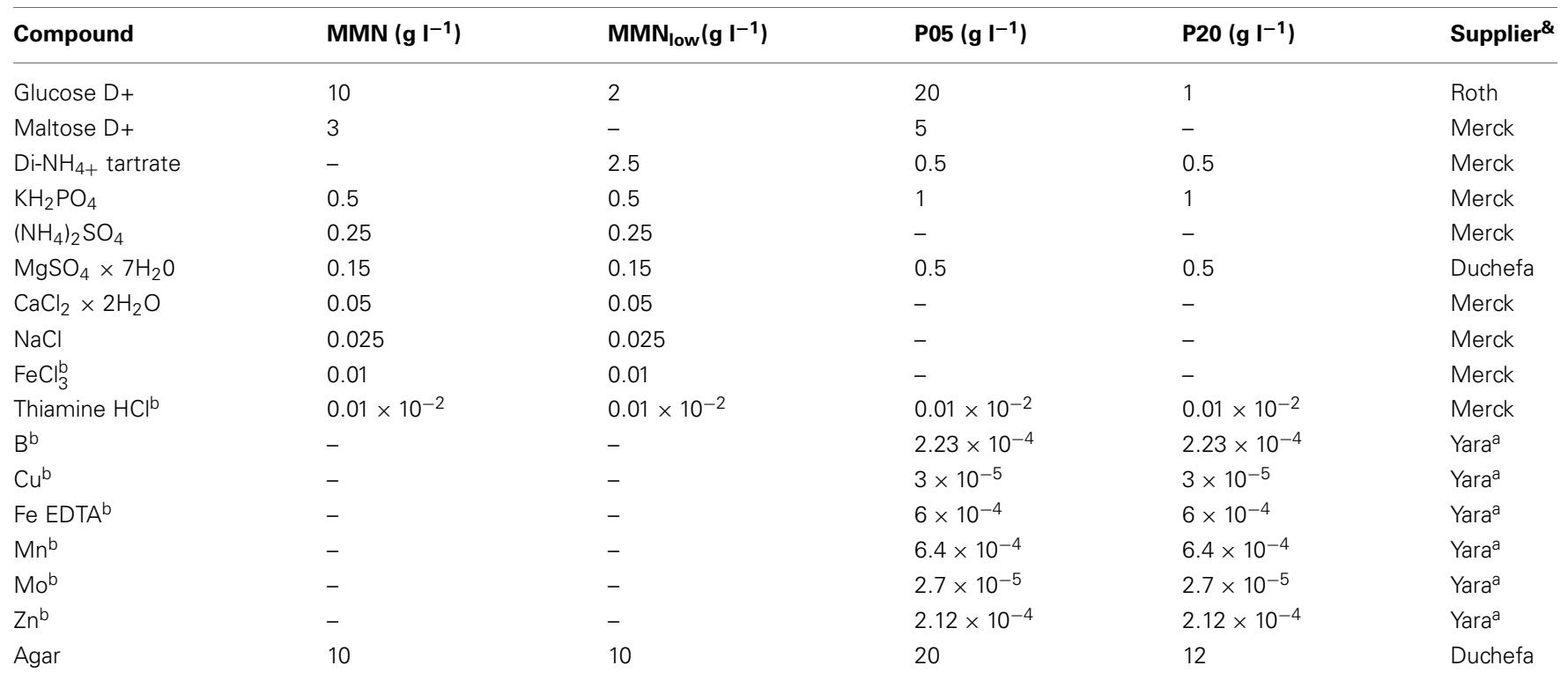

The concentrations are given as final concentrations.

Before Agar was added the $\mathrm{pH}$ of the media was adjusted with $\mathrm{NaOH}$ or $\mathrm{HCl}$. The MMN medium was adjusted to 5.2 and the pH of the P05 and P2O medium was adjusted to 5.8. The total volume of the media was brought to $1 \mathrm{~L}$ with distilled $\mathrm{H}_{2} \mathrm{O}$ before sterilization by autoclaving at $121^{\circ} \mathrm{C}$ for $20 \mathrm{~min}$ at 2.2 bar.

\& Suppliers: Carl Roth, Karlsruhe, Germany; Merck, Darmstadt, Germany; Duchefa, Haarlem, Netherlands; Yara Nanterre Cedex, France.

a The microelement solution Kanieltra from Yara, which contained B, Cu, Fe EDTA, Mn, Mo, and Zn, was used in a stock solution of $10 \%$ (v/v).

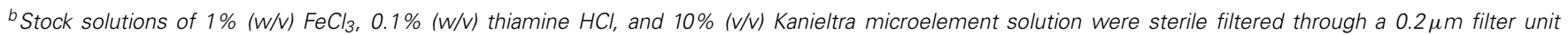

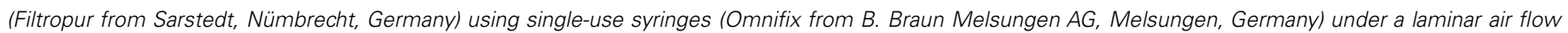

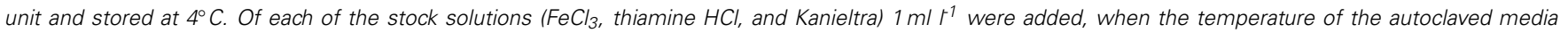
was $\sim 60^{\circ} \mathrm{C}$. 


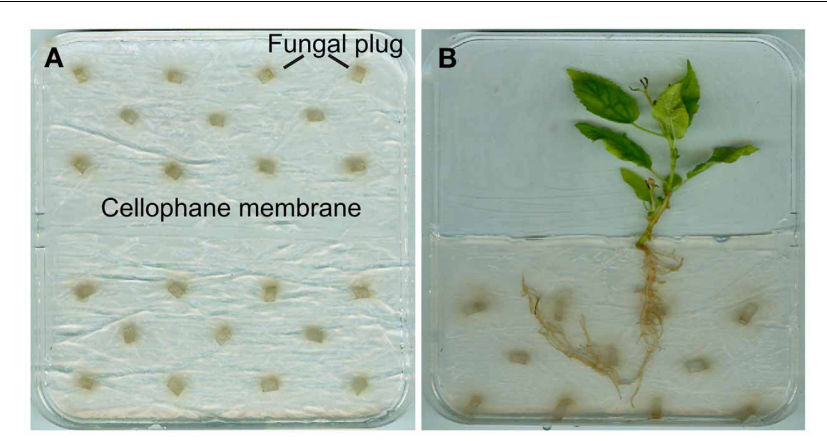

FIGURE 5 | Cocultivation of Populus $\times$ canescens with $L$. bicolor under axenic conditions. (A) Preculture of $L$. bicolor in a Petri dish on a cellophane membrane on P20 medium. It is possible to equip this system with two membranes in one Petri dish. (B) Cocultivation of $P \times$ canescens with L. bicolor.

(as described above). For the cocultivation square Petri dishes $(12 \times 12 \mathrm{~cm})$ containing $50 \mathrm{ml}$ of sugar-reduced P20 medium were used. After solidification, the upper half of the medium in the Petri dish was removed. The remaining medium was covered by a cellophane membrane $(6 \times 12 \mathrm{~cm})$ with or without 10 days old fungal mycelium of L. bicolor, pregrown on P20 media. A 3-week old, rooted poplar plantlet was placed on the fungal mycelium (Figure 5B). The shoot and leaves of the plant were located in the empty half of the Petri dish. The Petri dishes were sealed with Parafilm. To prevent exposure of the roots and the fungal mycelium to light, the lower halves of the Petri dishes were wrapped in aluminium foil. The plates were arranged vertically in racks and kept in a growth room at $26^{\circ} \mathrm{C}$ with a day/night cycle of $16 \mathrm{~h} / 8 \mathrm{~h}$. In general, the cultivation period of poplars in this system is limited by the size of the Petri dish, the size of the plantlets and the nutrient availability. In our experiments, poplar plantlets did not show symptoms of nutrient deficiencies or shortage of space during the 21 days of their growth.

To grow slightly larger mycorrhizal plants under axenic conditions, another co-culture system was used for the mycorrhization of Populus $\times$ canescens with the ectomycorrhizal fungus, Paxillus involutus. The fungal strains $P$. involutus NAU and MAJ were maintained on MMN media. For precultivation of the fungi, Petri dishes (diameter: $15 \mathrm{~cm}$ ) were filled with $15 \mathrm{ml}$ of a modified low carbohydrate $\mathrm{MMN}$ media $\left(\mathrm{MMN}_{\text {low }}\right.$; Table 3). A sterilized cellophane membrane (diameter: $7 \mathrm{~cm}$ ) was placed on the agar and a mycelium plug of either $P$. involutus MAJ or NAU was placed on to the cellophane membrane. The poplar plantlets were pregrown for 3 weeks in glass jars, which contained $160 \mathrm{ml}$ MMN media.

To assemble the plant-Petri dish system, a hole $(8 \mathrm{~mm})$ was made in the sidewall of the Petri dish using a hot forceps. The shoot of about 3-week-old poplar plantlets was placed outside the Petri dish, whereas the roots were spread either on noninoculated medium (Figure 6A) or on the 2-week-old fungal mycelium (Figure 6B). The Petri dishes were closed with Parafilm and wrapped in aluminum foil. They were placed in special planting chambers, which were covered with a translucent plastic top.
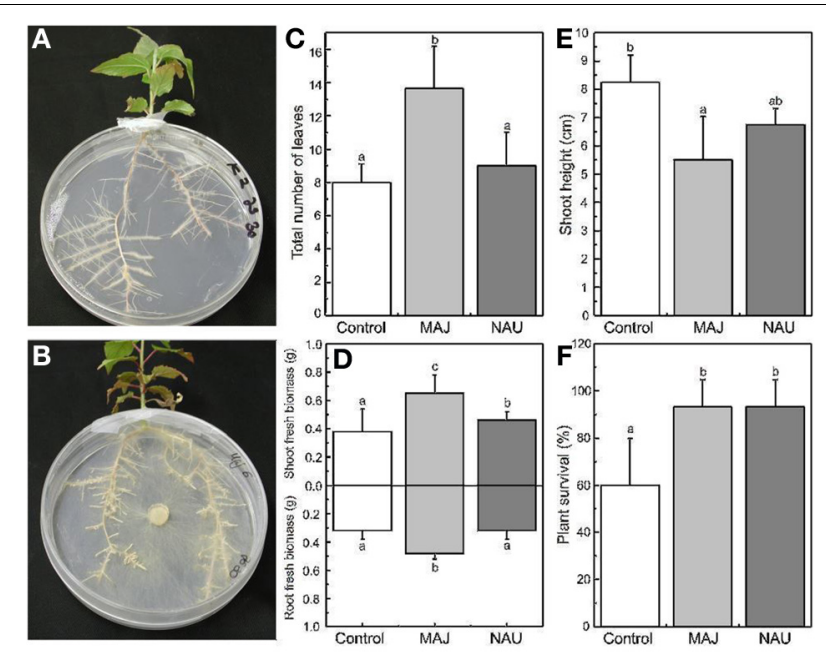

FIGURE 6 | Petri dish system for the cocultivation of Populus $\mathrm{x}$ canescens with $\boldsymbol{P}$ involutus under axenic conditions. All data are shown for plantlets 4 weeks after the transfer into the Petri dishes. (A) Control, non-mycorrhizal plantlet, and (B) mycorrhizal plantlet. (C) Total leaf number, (D) shoot and root biomass, and (E) shoot height of plantlets inoculated with $P$. involutus strain MAJ or strain NAU (mean $\pm \mathrm{SD}, n=5$ ). (F) Survival of non-inoculated control plantlets and plants inoculated with $P$. involutus strain MAJ or strain NAU (mean $\pm \mathrm{SD}, n=15$ ). Different letters indicate significant differences with $p<0.05$.

The system was maintained under high humidity of $70-75 \%$, a temperature of $22-23^{\circ} \mathrm{C}$ and $200 \mu \mathrm{mol} \mathrm{m} \mathrm{m}^{-2} \mathrm{~s}^{-1} \mathrm{PAR}$ in an acclimatized growth room. Especially, at the beginning the plants were very sensitive to desiccation and wilted easily. Furthermore, the system is more prone to infections by other microbes than the system in which the plants are grown completely inside the Petri dish and therefore has to be controlled regularly to discard contaminated dishes.

We cultured poplars and ectomycorrhizal fungi in this system for up to 4 weeks (Figures 6A,B). Figure 6B shows hyphae extending from the fungal plug to the roots. Poplars inoculated with $P$. involutus strain MAJ, which forms a functional mycorrhiza, developed more leaves, taller shoots, and more biomass than poplars without ectomycorrhiza (Figures 6C-E). In contrast to the strain MAJ, the strain NAU is not able to form functional ectomycorrhizas (Gafur et al., 2004), but nevertheless stimulated biomass production (Figure 6D) and increased the survival rate of the plantlets (Figure 6F). A closer inspection of the roots showed very dense formation of root hairs for the nonmycorrhizal plants (Figure 7A), coverage with a thin yellowish mycelium of the roots of the NAU inoculated plants (Figure 7B) and the characteristic extramatrical mycelium around new root tips and typical dichotomously branched roots for the MAJ inoculated plants (Figure 7C).

Controlled poplar-ectomycorrhizal systems are most useful to investigate the molecular basis of plant-fungal interactions and to analyze the biochemical composition of fungus, plants, and their combination without confounding effects of interfering organisms (e.g., Felten et al., 2009; Reich et al., 2009). 


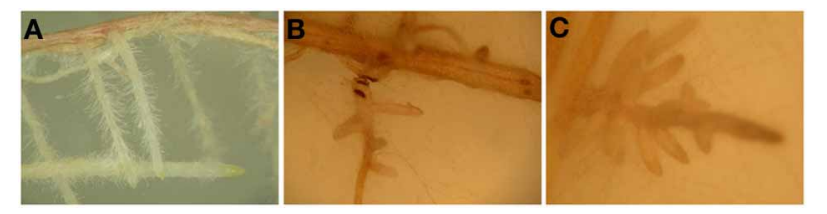

FIGURE 7 | Mycorrhizal and non-mycorrhizal roots of $\boldsymbol{P} \times$ canescens. All pictures were taken 4 weeks after transfer into the Petri dishes. (A) Root of a control plant with dense root hairs, (B) Changes in root tip morphology induced by Paxillus involutus strain NAU with a weak mycelium and brownish spots, and (C) typical dichotomously branched root tips with dense mycelium of $P$. involutus strain MAJ.

\section{COCULTIVATION UNDER OUTDOOR CONDITIONS}

To investigate non-mycorrhizal and mycorrhizal poplars under greenhouse or outdoor conditions, we employed different inoculation techniques: (a) cocultivation of the plant with the fungus in vitro and transfer of the mycorrhizal plants into soil. This results in high mycorrhization rates, but is very time consuming; (b) direct transfer of micropropagated Populus $\times$ canescens plants into soil, which had been mixed with homogenized, liquid cultures of the ectomycorrhizal fungus as described by Langenfeld-Heyser et al. (2007). Non-inoculated control plants have to be planted into soil which had been mixed with culture medium. It is also possible to pre-cultivate the plants in hydroponic solution. This intermediate step is more time-consuming, but generally leads to stronger plants; (c) direct transfer of micropropagated Populus $\times$ canescens plants into soil together with solid fungal inoculum. Because the protocols (a) and (b) have already been described in a detailed manner (Gafur et al., 2004; Langenfeld-Heyser et al., 2007; Beniwal et al., 2010), we describe here protocol (c).

L. bicolor was cultivated in Petri dishes (diameter: $10 \mathrm{~cm}$ ) on the solid media MMN (Table 2) for 3 weeks at $23^{\circ} \mathrm{C}$ in darkness (Figure 8D). One fungal plug was placed in the center of the medium. For control plants, Petri dishes with media but without fungus were prepared. After 3 weeks the total content of one Petri dish with or without fungal mycelium was cut into small pieces using a scalpel and mixed into $660 \mathrm{ml}$ of a sand/peat mixture. The sand/peat mixture has been described above.

In another approach the fungus was pre-grown on sand, which has the advantage that agar or Gelrite media are not transferred along with the fungus into the co-culture system. For this purpose a sandwich medium was prepared. The bottom of a Petri dish (diameter: $10 \mathrm{~cm}$ ) was filled with $30 \mathrm{ml}$ modified MMN media (Table 2). A cellophane membrane that had been boiled twice in distilled water $(30 \mathrm{~min})$ and autoclaved twice was placed on top of solidified medium. Then $70 \mathrm{~g}$ autoclaved sand was filled on the medium and a plug of vigorously growing mycelium was placed in the center on the sand (Figure 8D). Two ml autoclaved liquid MMN medium (diluted 1:1) was added. The plates were incubated at $23^{\circ} \mathrm{C}$ in permanent darkness. After 3 weeks the fungal mycelium had grown throughout the sand, but the cellophane membrane prevented direct growth into the solidified medium. For controls, sand without the addition of fungal plugs was prepared in the same way. The sand of one Petri dish with or without

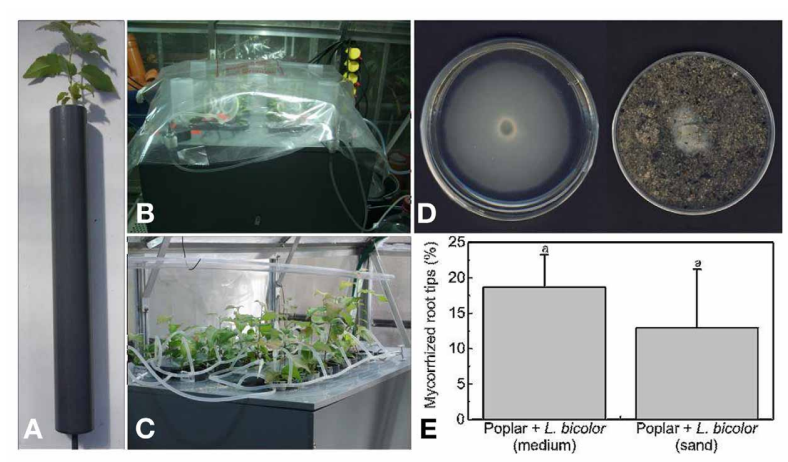

FIGURE 8 | Cocultivation of $\boldsymbol{P} \times$ canescens with $\boldsymbol{L}$. bicolor in growth tubes. $P . \times$ canescens plants in growth tubes with a sand/peat mixture (A), plants in the acclimatization phase covered with a transparent plastic bag (B), removal of the bags after 2 weeks (C), pre-grown L. bicolor in Petri dishes on agar media or sand (D), percentage of mycorrhizal root tips of $P$. $\times$ canescens grown in a sand/peat mixture inoculated with L. bicolor pregrown on agar medium or sand $(E)$ (mean $\pm S E, n=5)$. The same letters indicate the absence of significant difference with $p<0.05$.

L. bicolor was mixed with $660 \mathrm{ml}$ of the sand/peat mixture [two parts peat (REWE, Köln, Germany), eight parts coarse sand ( $\varnothing$ 0.71-1.25 mm Melo, Göttingen, Germany) and two parts fine sand ( $\varnothing 0.4-0.8 \mathrm{~mm}$ Melo, Göttingen).].

$P . \times$ canescens plantlets were rooted as described above and either planted directly into soil or after 2 weeks of hydroponic growth in LA solution. Prior to use the sand/peat mixture was mixed with the pieces of the solid medium or the sand, in which L. bicolor had been grown for 3 weeks. Six hundred and sixty milliliters sand/peat mixture with or without L. bicolor was filled in one growth tube (diameter $=5 \mathrm{~cm}$, length $=41 \mathrm{~cm}$; Figure 8A). The plants were planted into the growth tubes and immediately irrigated. The growth tubes were placed vertically in a specially designed PVC box (Figure 8B). To protect the plants against evaporation they were initially covered with transparent plastic bags (Figure 8B). The plastic bags were gradually lifted during the course of 2 weeks (Figure 8C). The plants were automatically irrigated with $10 \mathrm{ml}$ of LA solution three times daily. For irrigation, a 5 L bottle (Schott, Jena, Germany) was filled with the nutrient solution and set under an air pressure of $50 \mathrm{kPA}$ by an electronic pump (N022 AN1.8 from KNF Neuberger, Freiburg, Germany). The bottle was connected by an irrigation system of silicon tubes (Carl Roth, Karlsruhe, Germany) with each plant. The irrigation system was comprised of silicon tubes, T-pieces (Carl Roth, Karlsruhe, Germany), a magnetic valve (Bürkert, Ingelfingen, Germany) and $200 \mu$ l pipette tips (Sarstedt, Nümbrecht, Germany), which were placed in the growth tubes and served as nozzles. The irrigation was controlled with an integrated magnetic valve. The magnetic valve was connected to an electronic timer (Grässlin, Georgen, Germany) and opened every $8 \mathrm{~h}$ for $20 \mathrm{~s}$ when the bottle was under pressure. Excess solution could flow off through a hole at the bottom of the growth tubes. The plants were grown under controlled environment conditions with a $16 \mathrm{~h}$ light and $8 \mathrm{~h}$ darkness rhythm. After 21 days, about 13-19\% of the roots were mycorrhized with 
L. bicolor (Figure 8E). These mycorrhization rates were similar to those observed for axenic poplars on agar or gelrite plates (Figure 8E). After longer incubation times, the colonization rate of the root tips was further increased. This and similar culture systems have been successfully applied to study the influence of the EMF on plant stress tolerance and nutrient uptake (Brandes et al., 1998; Luo et al., 2009; Li et al., 2012).

\section{CONCLUSIONS AND OUTLOOK}

Growing poplars for research requires the careful selection of suitable growth conditions for various poplar species. In this method paper, reliable and well-established techniques for experimental setups with poplar under axenic and outdoor conditions have been described and illustrated by examples. To synthetize ectomycorrhizal poplars, the plant, and the fungus have to be pregrown in parallel, which has to be planned carefully. An overview of cultivation options and growing periods for research on poplars with and without mycorrhiza is summarized in the flow chart (Figure 1). Co-culture of poplars with ectomycorrhizal fungi promoted plant growth and vitality in vivo and in vitro. After extended co-cultivation mycorrhization rates in the range of $50-60 \%$ of the root tips can be found (e.g., Luo et al., 2009). Similarly, the colonization of field grown poplars is initially low, but increases to almost $100 \%$ in second year after planting (Danielsen et al., 2013). Therefore, the conditions reported here result in realistic EMF colonization rates.

We also reported the in vitro propagation of different poplars species which are particularly useful for specific research areas. $P . \times$ canescens is widely used because well-established transformation protocols exist for this hybrid for a long time (Leplé

\section{REFERENCES}

Altman, A. (2003). From plant tissue culture to biotechnology: scientific revolutions, abiotic stress tolerance, and forestry. In Vitro Cell. Dev. Biol. Plant 39, 75-84. doi: 10.1079/IVP2002379

Behnke, K., Grote, R., Brüggemann, N., Zimmer, I., Zhou, G., Elobeid, M., et al. (2012). Isoprene emissionfree poplars - a chance to reduce the impact from poplar plantations on the atmosphere. New Phytol. 194, 70-82. doi: 10.1111/j.14698137.2011.03979.x

Behnke, K., Kaiser, A., Zimmer, I., Brüggemann, N., Janz, D., Polle, A., et al. (2010). RNAi-mediated suppression of isoprene emission in poplar transiently impacts phenolic metabolism under high temperature and high light intensities: a transcriptomic and metabolomic analysis. Plant Mol. Biol. 74, 61-75. doi: 10.1007/s11103-010-9654-z

Beniwal, R. S., Langenfeld-Heyser, R., and Polle, A. (2010). Ectomycorrhiza and hydrogel protect hybrid poplar from water deficit and unravel plastic responses of xylem anatomy.

et al., 1992). P. euphratica is now the best investigated model tree to study salt tolerance in woody species (Chen and Polle, 2010). P. trichocarpa is a riparian species of high commercial value because it can be used for the production of fast-growing hybrids. The Eurasian aspen, $P$. tremula occurs on marginal soils and in forests, and therefore, is currently of increasing interest to study adaption to drought and nutrient stress (Kleemann et al., 2011; Euring et al., 2012). With exception of aspen, the other poplar species can easily be multiplied by woody cuttings. However, for a homogeneous quality of the plant material, the use of micro-propagated material is strongly recommended. Furthermore, plants for experiments can be produced at any time, whereas the best time to obtain woody cuttings is late winter.

\section{ACKNOWLEDGMENTS}

We thank our excellent technical assistants Christine Kettner, Gabriele Lehmann, and Marianne Smiatacz for their skillful and reliable support. We thank Mareike Kavka (Laboratory for Radio-Isotopes) and Mohammad Tanbir Habib for providing the photos of a poplar (Figure 8B) and the cellophane coated plates (Figure 5), respectively. We are grateful to the Federal Government of Lower Saxony (Niedersächsisches Ministerium für Wissenschaft und Kultur) and the "Niedersächsisches Vorab" for funding the Cluster of Excellence "Functional Biodiversity Research" and to the German Science Foundation (DFG) for financial support to the project "Poplar communication" (Po362/20). We are also indebted to the DFG and the Open Access Publication Funds of the Georg-August University of Göttingen for a publication grant.

(2003). In vitro culture and genetic engineering of Populus spp.: synergy for forest tree improvement. Plant Cell Tiss. Org. Cult. 72, 109-138. doi: 10.1023/A:1022265504775

Cooke, J. E., and Weih, M. (2005). Nitrogen storage and seasonal nitrogen cycling in Populus: bridging molecular physiology and ecophysiology. New Phytol. 167, 19-30. doi 10.1111/j.1469-8137.2005.01451.x

Danielsen, L., Lohaus, G., Sirrenberg, A., Karlovsky, P., Bastien, C., Pilate, G., et al. (2013). Ectomycorrhizal colonization and diversity in relation to tree biomass and nutrition in a plantation of transgenic poplars with modified lignin biosynthesis. PLOS ONE 8:e59207. doi: 10.1371/journal.pone.0059207

Danielsen, L., Thürmer, A., Meinicke, P., Buée, M., Morin, E., Martin, F., et al. (2012). Fungal soil communities in a young transgenic poplar plantation form a rich reservoir for fungal root communities. Ecol. Evol. 2, 1935-1948. doi: 10.1002/ece3.305

Deveau, A., Palin, B., Delaruelle, C., Peter, M., Kohler, A., Pierrat, J. C., et al. (2007). The mycorrhiza helper Pseudomonas fluorescens BBc6R8 has a specific priming effect on the growth, morphology and gene expression of the ectomycorrhizal fungus Laccaria bicolor S238N. New Phytol. 175, 743-755. doi: 10.1111/j.1469-8137.2007.02148.x

Dickmann, D. I. (2001). "An overview of the genus Populus," in Poplar Culture in North America, Part A, eds D. I. Dickmann, J. G. Isebrands, J. E. Eckenwalder, and J. Richardson (Ottawa, CA: NRC Research), $1-42$.

Doty, S. L. (2008). Enhancing phytoremediation through the use of transgenics and endophytes. New Phytol. 179, 318-333. doi: 10.1111/j.14698137.2008.02446.x

Eckenwalder, J. E. (1996). "Systematics and evolution of Populus," in Biology of Populus and its Implications for Management and Conservation, eds R. F. Stettler, H. D. Jr. Bradshaw, P. E. Heilman, and T. M. Hinckley (Ottawa, CA: NRC Research), 7-32.

Elobeid, M., Gobel, C., Feussner, I., and Polle, A. (2011). Cadmium interferes with auxin physiology and lignification in poplar. J. Exp. Bot. 63, 1413-1421. doi: 10.1093/jxb/err384 
Elobeid, M., and Polle, A. (2012). "Interference of heavy metal toxicity with auxin physiology," in Metal Toxicity in Plants: Perception, Signaling and Remediation, eds D. K. Gupta and L. M. Sandalio (Berlin, Heidelberg: Springer Berlin Heidelberg), 249-259. doi: 10.1007/978-3-642-22081-4_12

Euring, D., Löfke, C., Teichmann, T., and Polle, A. (2012). Nitrogen fertilization has differential effects on $\mathrm{N}$ allocation and lignin in two Populus species with contrasting ecology. Trees 26, 1933-1942. doi: 10.1007/s00468-012-0761-0

Felten, J., Kohler, A., Morin, E., Bhalerao, R. P., Palme, K., Martin, F., et al. (2009). The ectomycorrhizal fungus Laccaria bicolor stimulates lateral root formation in poplar and Arabidopsis through auxin transport and signaling. Plant Physiol. 151, 1991-2005. doi: 10.1104/pp.109.147231

Gafur, A., Schützendübel, A., Langenfeld-Heyser, R., Fritz, E., and Polle, A. (2004). Compatible and incompetent Paxillus involutus isolates for ectomycorrhiza formation in vitro with poplar (Populus $\times$ canescens) differ in $\mathrm{H}_{2} \mathrm{O}_{2}$ production. Plant Biol. 6, 91-99. doi: 10.1055/s-2003-44718

Habib, M. T., Heller, T., and Polle, A. (2013). "Molecular physiology of tree ectomycorrhizal interactions," in Plant Roots: The Hidden Half, 4th edn., eds A. Eshel and T. Beeckman (Boca Raton, FL: CRC Press), 39.1-39.21.

Häggman, H., Sutela, S., and Welander, M. (2007). "Micropropagation of Betula pendula Roth. including genetically modified material," in Protocols for Micropropagation of Woody Trees and Fruits, eds S. M. Jain and H. Häggman (Dordrecht, Springer Netherlands), 153-162. doi: 10.1007/978-1-40206352-7_15

Harvey, H. P., and van den Driessche, R. (1997). Nutrition, xylem cavitation and drought resistance in hybrid poplar. Tree Physiol. 17, 647-654. doi: 10.1093/treephys/17.10.647

Henrion, B., Battista, C. D., Bouchard, D., Vairelles, D., Thompson, B. D., Tacon, F. L., et al. (1994). Monitoring the persistence of Laccaria bicolor as an ectomycorrhizal symbiont of nursery-grown Douglas fir by PCR of the rDNA intergenic spacer. Mol. Ecol. 3, 571-580. doi: 10.1111/j.1365294X.1994.tb00088.x

Hewitt, E. J., and Smith, T. A. (1975). Plant Mineral Nutrition. London: English U.P.
Iordan-Costache, M., Lowe, K. C., Davey, M. R., and Power, J. B. (1995). Improved micropropagation of Populus spp. by Pluronic F68. Plant Growth Regul. 17, 233-239. doi: 10.1007/BF00024731

Janz, D., Behnke, K., Schnitzler, J. P., Kanawati, B., Schmitt-Kopplin, P., and Polle, A. (2010). Pathway analysis of the transcriptome and metabolome of salt sensitive and tolerant poplar species reveals evolutionary adaption of stress tolerance mechanisms. BMC Plant Biol. 10:150. doi: 10.1186/1471-2229-10150

Janz, D., Lautner, S., Wildhagen, H., Behnke, K., Schnitzler, J.-P., Rennenberg, H., et al. (2012). Salt stress induces the formation of a novel type of "pressure wood" in two Populus species. New Phytol. 194, 129-141. doi: 10.1111/j.1469-8137.2011.03975.x

Kang, B., Osburn, L., Kopsell, D., Tuskan, G. A., and Cheng, Z.M. (2009). Micropropagation of Populus trichocarpa 'Nisqually-1': the genotype deriving the Populus reference genome. Plant Cell Tiss. Org. Cult. 99, 251-257. doi: 10.1007/s11240-009-9596-9

Kang, H., and Chun, Y. W. (1997). "Plant regeneration through organogenesis in poplar," in Micropropagation, Genetic Engineering, and Molecular Biology of Populus, eds N. B. Klopfenstein, Y. W. Chun, M.-S. Kim, and M. A. Ahuja (Fort Collins, CO: USDA Forest Service Gen. Tech. Rep. RM-GTR-297), 326-336.

Kleemann, F., von Fragstein, M., Vornam, B., Müller, A., Leuschner, C., Holzschuh, A., et al. (2011). Relating genetic variation of ecologically important tree traits to associated organisms in full-sib aspen families. Eur. J. For. Res. 130, 707-716. doi: 10.1007/s10342-010-0460-6

Lang, C., Seven, J., and Polle, A. (2011). Host preferences and differential contributions of deciduous tree species shape mycorrhizal species richness in a mixed Central European forest. Mycorrhiza 21, 297-308. doi: 10.1007/s00572-0100338-y

Langenfeld-Heyser, R., Gao, J., Ducic, T., Tachd, P., Lu, C. F., Fritz, E., et al. (2007). Paxillus involutus mycorrhiza attenuate $\mathrm{NaCl}$-stress responses in the salt-sensitive hybrid poplar Populus $\times$ canescens. Mycorrhiza 17, 121-131. doi: 10.1007/s00572-006-0084-3

Larisch, C., Dittrich, M., Wildhagen, H., Lautner, S., Fromm, J., Polle,
A., et al. (2012). Poplar wood rays are involved in seasonal remodeling of tree physiology. Plant Physiol. 160, 1515-1529. doi: 10.1104/pp.112.202291

Leplé, J. C., Brasileiro, A. C. M., Michel, M. F., Delmotte, F., and Jouanin, L. (1992). Transgenic poplars: expression of chimeric genes using four different constructs. Plant Cell Rep. 11, 137-141. doi: 10.1007/BF00232166

Li, J., Bao, S., Zhang, Y., Ma, X., Mishra-Knyrim, M., Sun, J., et al. (2012). Paxillus involutus strains MAJ and NAU mediate $\mathrm{K}+/ \mathrm{Na}+$ homeostasis in ectomycorrhizal Populus $\times$ canescen under sodium chloride stress. Plant Physiol. 159, 1771-1786. doi: 10.1104/pp.112.195370

Lloyd, G., and McCown, B. H. (1980). Commercially-feasible micropropagation of mountain laurel, Kalmia latifolia, by use of shoot-tip culture. Proc. Int. Plant Prop. Soc. 30, 421-427.

Lubrano, L. (1992). "Microproagation of poplars (Populus spp.)," in Agriculture and Forestry, Vol. 18, High-Tech and Micropropagation II, ed Y. P. S. Bajaj (Berlin: Springer), 151-178. doi: 10.1007/978-3-642-76422-6_8

Lukac, M., Calfapietra, C., Lagomarsino, A., and Loreto, F. (2010). Global climate change and tree nutrition: effects of elevated $\mathrm{CO}_{2}$ and temperature. Tree Physiol. 30, 1209-1220. doi: 10.1093/treephys/tpq040

Luo, Z.-B., Janz, D., Jiang, X., Göbel, C., Wildhagen, H., Tan, Y., et al. (2009). Upgrading root physiology for stress tolerance by ectomycorrhizas: insights from metabolite and transcriptional profiling into reprogramming for stress anticipation. Plant Physiol. 151, 1902-1917. doi: 10.1104/pp.109.143735

Maheshwari, P., and Kovalchuk, I. (2011). Efficient shoot regeneration from internodal explants of Populus angustifolia, Populus balsamifera and Populus deltoids. New Biotechnol. 28, 778-787. doi: 10.1016/j.nbt.2011. 05.005

Marmeisse, R., Nehls, U., Öpik, M., Selosse, M. A., and Pringle, A. (2013). Bridging mycorrhizal genomics, metagenomics and forest ecology. New Phytol. 198, 343-346. doi: 10.1111/nph.12205

Martin, F., Aerts, A., Ahrén, D., Brun, A., Duchaussoy, F., Kohler, A., et al. (2008). The genome sequence of Laccaria bicolor provides insights into the mycorrhizal symbiosis. Nature 452, 88-92. doi: 10.1038/nature06556

Marx, D. H. (1969). The influence of ectotrophic mycorrhizal fungi on the resistance of pine roots to pathogenic infections. I. Antagonism of mycorrhizal fungi to root pathogenic fungi and soil bacteria. Phytopathology 59, 153-163.

McCown, B. H. (1997). "Poplar shoot cultures: their generation and use in biotechnology," in Micropropagation, Genetic Engineering, and Molecular Biology of Populus, eds N. B. Klopfenstein, Y. W. Chun, M.S. Kim, and M. A. Ahuja (Fort Collins, CO: USDA Forest Service Gen. Tech. Rep. RM-GTR-297), 326-335.

Müller, A., Faubert, P., Hagen, M., zu Castell, W., Polle, A., Schnitzler, J.-P., et al. (2013). Volatile profiles of fungi - chemotyping of species and ecological functions. Fungal Genet. Biol. 54, 25-33. doi: 10.1016/j.fgb.2013.02.005

Murashige, T., and Skoog, F. (1962). A revised medium for rapid growth and bio assays with tobacco tissue cultures. Physiol. Plant. 15, 473-497. doi: 10.1111/j.13993054.1962.tb08052.x

Nehls, U., Göhringer, F., Wittulsky, S., and Dietz, S. (2010). Fungal carbohydrate support in the ectomycorrhizal symbiosis: a review. Plant Biol. 12, 292-301. doi: 10.1111/j.1438-8677.2009.00312.x

Noël, N., Leple, J. C., and Pilate, G. (2002). Optimization of in vitro micropropagation and regeneration for Populus $\times$ interamericana and Populus $\times$ euramericana hybrids (P. deltoides, P. trichocarpa, and $P$. nigra). Plant Cell Rep. 20, 1150-1155. doi: 10.1007/s00299-002-0465-9

Nool, N., Leplé, J. C., and Pilate, G. (2002). Optimization of in vitro micro propagation and regeneration for Populus $\times$ interamericana and Populus $\mathrm{x}$ euramericana hybrids (P. deltoides, P. trichocarpa, and P. nigra). Plant Cell Rep. 20, 1150-1155. doi: 10.1007/s00299-002-0465-9

Peternel, Š., Gabrovšek, K., Gogala, N., and Regvar, M. (2009). In vitro propagation of European aspen (Populus tremula L.) from axillary buds via organogenesis. Sci. Hortic. 121, 109-112. doi: 10.1016/j.scienta.2009.01.010

Phan, T. C., Jorgensen, J., Jouve, L., Hausman, J. F., Polle, A., and Teichmann, T. (2004). Micropropagation of Populus 
euphratica Olivier. Belg. J. Bot. 137, Reich, M., Göbel, C., Kohler, A., 175-180.

Philippe, R. N., and Bohlmann, J. (2007). Poplar defense against insect herbivores. Can.J. Bot. 85, 1111-1126. doi: 10.1139/B07-109

Pilate, G., Chabbert, B., Cathala, B., Yoshinaga, A., Leplé, J. C., Laurans, F., et al. (2004). Lignification and tension wood. C. R. Biol. 327, 889-901. doi: 10.1016/j.crvi.2004.07.006

Plomion, C., Leprovost, G., and Stokes, A. (2001). Wood formation in trees. Plant Physiol. 127, 1513-1523. doi: 10.1104/pp.010816

Polle, A., and Douglas, C. (2010). The molecular physiology of poplars: paving the way for knowledge-based biomass production. Plant Biol. 12, 239-241. doi: 10.1111/j.14388677.2009.00318.x

Polle, A., Janz, D., Teichmann, T., and Lipka, V. (2013). Poplar genetic engineering: promoting desirable wood characteristics and pest resistance. Appl. Microbiol. Biotechnol. 97, 5669-5679.

Poorter, H., Fiorani, F., Stitt, M., Schurr, U., Finck, A., Gibon, Y., et al. (2012). The art of growing plants for experimental purposes: a practical guide for the plant biologist. Funct. Plant Biol. 39, 821-838. doi: 10.1071/FP12028

Pospóšilová, J., Tichá, I., Kadleèek, P., Haisel, D., and Plzáková, Š. (1999). Acclimatization of micropropagated plants to ex vitro conditions. Biol. Plant. 42, 481-497. doi: 10.1023/A:1002688208758
Buée, M., Martin, F., Feussner, I., et al. (2009). Fatty acid metabolism in the ectomycorrhizal fungus Laccaria bicolor. New Phytol. 182, 950-964. doi: 10.1111/j.1469-8137.2009.02819.x

Rennenberg, H., Wildhagen, H., and Ehlting, B. (2010). Nitrogen nutrition of poplar trees. Plant Biol. 12, 275-291. doi: 10.1111/j.14388677.2009.00309.x

Rohde, A., Storme, V., Jorge, V., Gaudet, M., Vitacolonna, N., Fabbrini, F., et al. (2011). Bud set in poplar - genetic dissection of a complex trait in natural and hybrid populations. New Phytol. 189, 106-121. doi: 10.1111/j.1469-8137.2010.03469.x

Sannigrahi, P., Ragauskas, A. J., and Tuskan, G. A. (2010). Poplar as a feedstock for biofuels: a review of compositional characteristics. Biofuels Bioprod. Biorefin. 4, 209-226. doi: 10.1002/bbb.206

Schenk, R. U., and Hildebrandt, A. C. (1972). Medium and techniques for induction and growth of monoplant cell cultures. Can. J. Bot. 50, 199-204. doi: 10.1139/b72-026

Schnitzler, J. P., Louis, S., Behnke, K., and Loivamäki, M. (2010). Poplar volatiles-biosynthesis, regulation and (eco) physiology of isoprene and stress-induced isoprenoids. Plant Biol. 12, 302-316. doi: 10.1111/j.1438-8677.2009.00284.x

Strauss, S. H., Tan, H., Boerjan, W. and Sedjo, R. (2009). Strangled cotyledonous and dicotyledonous at birth. Forest biotech and the convention on biological diversity. Nat. Biotechnol. 27, 519-527. doi: 10.1038/nbt0609-519

Thakur, A. K., Saraswat, A., and Srivastava, D. K. (2012). In vitro plant regeneration through direct organogenesis in Populus deltoides clone G48 from petiole explants. J. Plant Biochem. Biotechnol. 21, 23-29. doi: 10.1007/s13562-011-0067-0

Tuskan, G. A., DiFazio, S., Jansson, S. Bohlmann, J., Grigoriev, I., Hellsten, U., et al. (2006). The genome of black cottonwood, Populus trichocarpa (Torr. and Gray). Science 313, 1596-1604. doi: 10.1126/science. 1128691

Vinocur, B., Carmi, T., Altman, A. and Ziv, M. (2000). Enhanced bud regeneration in aspen (Populus tremula L.) roots cultured in liquid media. Plant Cell Rep. 19, 1146-1154. doi: $10.1007 / \mathrm{s} 002990000243$

Walter, C., Fladung, M., and Boerjan, W. (2010). The 20-year environmental safety record of GM trees. Nat. Biotechnol. 28, 656-658. doi 10.1038/nbt0710-656

Wullschleger, S. D., Weston, D. J. and Davis, J. M. (2009). Populus responses to edaphic and climatic cues: emerging evidence from systems biology research. Crit. Rev. Plant Sci. 28, 368-374. doi: 10.1080/07352680903241246

Yadav, R., Arora, P., Kumar, D., Katyal, D., Dilbaghi, N., and Chaudhury, A (2009). High frequency direct plant regeneration from leaf, internode, and root segments of Eastern Cottonwood (Populus deltoides). Plant Biotechnol. Rep. 3, 175-182. doi: 10.1007/s11816-009-0088-5

Conflict of Interest Statement: The authors declare that the research was conducted in the absence of any commercial or financial relationships that could be construed as a potential conflict of interest.

Received: 14 June 2013; paper pending published: 18 July 2013; accepted: 06 August 2013; published online: 27 August 2013.

Citation: Müller A, Volmer K, MishraKnyrim M and Polle A (2013) Growing poplars for research with and without mycorrhizas. Front. Plant Sci. 4:332. doi: 10.3389/fpls.2013.00332

This article was submitted to Crop Science and Horticulture, a section of the journal Frontiers in Plant Science.

Copyright (C) 2013 Müller, Volmer, Mishra-Knyrim and Polle. This is an open-access article distributed under the terms of the Creative Commons Attribution License (CCBY). The use, distribution or reproduction in other forums is permitted, provided the original author(s) or licensor are credited and that the original publication in this journal is cited, in accordance with accepted academic practice. No use, distribution or reproduction is permitted which does not comply with these terms. 